\title{
Percepção de docentes e discentes de nutrição sobre o profissional enfermeiro'
}

\author{
Maria Angela Boccara de Paula² \\ Adriana Giunta Cavaglieri 3 \\ Cristina Bicudo de Souza4 \\ Silvia Maira Pereira Cintra 5 \\ Leonília Vieira de Souza ${ }^{6}$ \\ Fernanda Testa Santos ${ }^{7}$
}

doi:10.11144/Javeriana.ie19-1.pddn

Cómo citar: Paula MAB, Cavaglieri AG, Souza MCB, Cintra SMP, Souza LV, Santos F.T Percepção de docentes e discentes de nutrição sobre o profissional enfermeiro. Investig Enferm. Imagen Desarr. 2017;19(1): 95-105. http://dx.doi.org/10.11144/Javeriana.ie191.pddn

1. Artículo original de investigación. Fecha de recepción: 16 de Marzo de 2015. Fecha de aceptación: 2 de Diciembre de 2015

2. Enfermeira estomaterapeuta. Professor Assistente doutor. Departamento de Enfermagem e Nutrição. Programa de Mestrado em desenvolvimento Humano: Formação, políticas e práticas Sociais. Universidade de Taubaté. Correio eletrônico:boccaradadepaula@, gmail.com

3. Enfermeira. Professor Assistente Doutor Departamento de Enfermagem e Nutrição. Universidade de Taubaté.

4. Enfermeira. Professor Assistente Doutor Departamento de Enfermagem e Nutrição Universidade de Taubaté.

5. Enfermeira. Professor mestre do Departamento de Enfermagem e Nutrição Universidade de Taubaté.

6. Enfermeira. Professor mestre do Departamento de Enfermagem e Nutrição Universidade de Taubaté.

7. Enfermeira graduada pela Universidade de Taubaté. Departamento de Enfermagem e Nutrição - Universidade de Taubaté. 


\section{Resumo}

Objetivo: Conhecer percepções de docentes e discentes de Nutrição sobre o enfermeiro. Métodos: Estudo qualitativo a luz da Teoria das Representações Sociais. População: quatro docentes, cinco discentes ingressantes e cinco concluintes do curso de nutrição de uma Universidade do Vale do Paraíba Paulista. Dados coletados setembro/ 2008, entrevistas semi estruturadas. Questão norteadora: ¿Qual sua percepção do enfermeiro no contexto de saúde? Resultados: Análise de conteúdo originou três Unidades Temáticas: área de atuação do enfermeiro, cuidado humanizado, papel do enfermeiro na equipe de saúde. Conclusão: Enfermeiros percebidos como importantes e atuantes diretamente com paciente, destacando-se cuidado humanizado. Por outro lado também percebido como profissional que tem ações atreladas especialmente ao médico. Suas ações não foram claramente delimitadas, demonstrando falta de clareza do seu papel no contexto de saúde.

Palavras-chave: Enfermeiro, Enfermagem, Docentes, Percepção

\section{Percepción de los profesores y estudiantes de la nutrición acerca del enfermero}

\section{Resumen}

Objetivo: conocer las percepciones de profesores y estudiantes de Nutrición sobre el enfermero. Método: estudio cualitativo basado en la Teoría de las Representaciones Sociales. Muestra: cuatro profesores del grado, cinco estudiantes principiantes y cinco concluyentes del Curso de Grado en Nutrición de la Universidad del Vale do Paraíba Paulista, el instrumento utilizado para la recolección de la información fue la entrevista semi-estructurada basada en la pregunta general: ¿Cuál es su percepción acerca del enfermero en el contexto de la salud? Los datos obtenidos fueron analizados de manera integral en sus contenidos. Resultados: a partir del análisis de contenido se generaron tres categorias Temáticas: área de operación del enfermero, atención humanizada, papel del enfermero en el equipo de salud. Conclusión: los enfermeros fueron percibidos por los profesores y estudiantes de nutrición como actores importantes en el cuidado puesto que trabajan directamente con el paciente, especialmente bajo una atención humanizada. Por otra parte, se percibió como un profesional que ha vinculado sus acciones, en el trabajo conjunto con el profesional médico. Sin embargo, los participantes del estudio perciben poca claridad de su rol y campos de acción en el contexto de la salud.

Palabras clave: enfermero; enfermería; docentes; percepción 


\section{Perception of Nutrition teachers and students about nurses}

\section{Abstract}

Objective: To know the perceptions of teachers and students of Nutrition about the nurse. Method: A qualitative study based on the Theory of Social Representations. Sample: four teachers from the level, five beginner students and five students near graduation from the Course Degree in Nutrition at the University of Vale do Paraiba Paulista. The instrument used for data collection was the semi -structured interview based on the general question: What is your perception of nurses in the context of health? The data obtained was holistically analyzed. Results: from the analysis of the content, three categories emerged: nurse's area of operation, humanized care, role of nurses in the health team. Conclusion: The nurses were perceived by teachers and students of nutrition as important actors in care since they work directly with the patient, especially under a humanized attention. Moreover, they were perceived as professionals who link their actions in working together with the doctor. However, the study participants perceived lack of clarity of their role and fields of action in the context of health.

Keywords: Nursing; teachers; perception 


\section{Introdução}

A Enfermagem profissão institucionalizada na Inglaterra tem como base de atuação o cuidado ao ser humano, seja na sua individualidade, na família ou comunidade, desenvolve ações de promoção, prevenção, recuperação e reabilitação junto à equipe de saúde. Seu papel muitas vezes esta imbricado com o de outros elementos da equipe de saúde o que por vezes o descaracteriza e o torna despersonalizado, especialmente pelo caráter funcional que a profissão assume devido a divisão técnica do seu trabalho em tarefas e procedimentos (1).

O enfermeiro é o responsável técnico direto pela equipe de enfermagem nos diferentes serviços de saúde, mas que também prima pela mediação entre profissionais de saúde e a pessoa assistida, contribuindo positivamente para maior interação entre eles, ampliando o espaço nas relações que ocorrem nas unidades de saúde.

A imagem profissional do enfermeiro sofre influência da sua história. A profissão surgiu como resposta ao desejo da manutenção da saúde das pessoas que se efetivava por meio da promoção de conforto e proteção aos doentes. Atividades realizadas especialmente por mulheres, que ao longo da história marcou a enfermagem como uma profissão predominantemente feminina. Sua história foi permeada por diferentes figuras femininas como de prisioneiras, prostitutas, bruxas e anjos. Essas imagens relacionam-se com questões que transitam desde a vocação e dedicação cristã até as penalidades aos desvios de caráter ou morais. Contudo, esses estereótipos, mesmo com a evolução da profissão, ainda persistem resquícios no imaginário social $(2,3)$.

O enfermeiro vem construindo seu espaço profissional e, gradativamente, ocupando novos lugares na equipe de saúde, por meio da aquisição de conhecimentos específicos que fundamentam seu saber - fazer e, desta forma, possibilitam a abertura de espaços ainda não ocupados pelos mesmos (3).

Ao fazer parte da equipe de saúde o enfermeiro mantém contato direto com os outros profissionais da equipe, sendo importante elo entre seus integrantes, paciente e família, especialmente devido a sua presença constante $(24 \mathrm{~h} / \mathrm{dia})$ principalmente no ambiente hospitalar. Seu papel se imbrica com de outros profissionais em todas as esferas assistenciais, portanto sua trajetória profissional vem se ampliando e assim seu papel e imagem profissional também sofrem transformações.

A equipe de enfermagem mantém estreita relação com a equipe de nutrição na sua prática clínica, assim o objetivo deste estudo foi conhecer as percepções de docentes e discentes de Nutrição sobre o profissional enfermeiro.

\section{Métodos}

Estudo de natureza descritiva, com abordagem qualitativa à Luz da Teoria das Representações Sociais (RS), definida como o estudo de fenômenos de um grupo específico e dos processos imaginários de seus integrantes, sendo assim produção simbólica, expressão dos sentidos e percepções que as pessoas têm dessa realidade (4). 
Projeto aprovado pelo Comitê de Ética em Pesquisa da Universidade de Taubaté (CEP n 167/08). Participaram quatro docentes da área profissionalizante, cinco discentes ingressantes e cinco concluintes do curso de graduação em nutrição de uma Universidade do Vale do Paraíba Paulista, que, após serem esclarecidos sobre o objetivo do estudo, assinaram o Termo de Consentimento Livre Esclarecido, conforme preconiza a resolução 466/2012 das Diretrizes e Normas Regulamentadoras de Pesquisas envolvendo seres humanos do Conselho Nacional de Saúde.

Os dados foram coletados por meio de entrevistas individuais, nas dependências do Departamento de Nutrição da Universidade, no mês de setembro de 2008.

O roteiro da entrevista foi composto por duas partes: a primeira, com dados de caracterização do participante, e a segunda, gravada em fita cassete, tendo como questão norteadora: ¿Qual é a sua percepção do enfermeiro no contexto de saúde?

Os resultados obtidos foram transcritos na íntegra e submetidos à análise de conteúdo (5), originando duas Unidades Temáticas: atuação do enfermeiro e papel do enfermeiro na equipe de saúde.

\section{Resultados y discusión}

Fizeram parte do estudo 14 pessoas, sendo quatro docentes (D) da área profissionalizante, cinco alunos ingressantes (DI), cinco alunos concluintes (DC) do curso de graduação em nutrição de uma instituição de ensino superior do Vale do Paraíba Paulista.

As quatro docentes participantes eram do sexo feminino. A predominância do sexo feminino está relacionada com a história da profissão de nutrição, que nasce da necessidade de organizar cozinhas funcionais para dietas de enfermos graves, bem como ao racionamento e provisão de alimentos em tempos de guerra (5), funções relacionadas ao papel da mulher na sociedade.

Quanto à titulação dos docentes participantes, três eram doutores e um mestre e o tempo de docência variou de um a nove anos, com média de quatro anos e dois meses, mostrando que os docentes buscavam a titulação acadêmica apesar de jovens na prática docente.

A idade dos docentes participantes variou de 32 a 47 anos, com média de 40 anos de idade.

Quanto aos alunos cinco eram ingressantes e cinco concluintes, sendo que oito eram mulheres e dois homens. Nenhum participante atuava na área da saúde.

\section{Unidade temática I - Atuação do enfermeiro}

A função básica do enfermeiro no contexto da saúde fundamenta-se no processo de cuidar. Conceito amplo que envolve múltiplos aspectos e centra-se na concepção de que o cuidado deve estar presente em tudo e vai além da atitude tecnológica, reconhece-se a todos numa condição de inter-relacionamento $(6,7)$. 
Sua atuação envolve diferentes áreas desde o campo assistencial, até áreas como consultoria, auditoria, docência, gerência e pesquisa em saúde em instituições hospitalares, empresas, escolas, clínicas médicas, ambulatórios, institutos de pesquisas dentre outros, desta forma apesar da profissão estar alicerçada na assistência, possui diferentes campos de atuação, por vezes pouco conhecidas pela sociedade em geral.

Os docentes participantes (D) desse estudo apontaram os enfermeiros como elementos importantes, considerados profissionais que atuam diretamente com o paciente e que se sobressaem na equipe de saúde, especialmente pelo cuidado humanizado, como é possivel verificar nos recortes abaixo.

Que realmente quer lidar com gente (D1).

Uma pessoa que tem um lado humano muito desenvolvido (D2).

A percepção atribuída ao enfermeiro nessas falas relaciona-se com a imagem da enfermagem centrada na "arte do cuidar", englobando cuidados técnicos /arte de fazer, com o cientifico/ uma ciência, e humano tendo sempre como base as relações interpessoais. Denota-se que a sua essência é o cuidado com as pessoas, integrados num modelo holístico, no qual a pessoa é vista na sua integralidade $(7,8)$.

Corroborando, os atributos de humanismo considerados como componentes do cuidar em enfermagem, tem sido identificados à imagem de um profissional bondoso, acessivel, preocupado com todas as dimensões que afetam o ser humano (2).

Por outro lado, recortes dos discursos coletados junto aos docentes apontaram que os enfermeiros se envolvem muito com a parte burocrática, gerencial do cuidado, se afastando da prevenção e tratamento, o que dificulta o estabelecimento do vínculo do profissional com a equipe no processo do cuidar do paciente. Essa situação referida pelos docentes, talvez tenha sido expressada em função do dia-a-dia do enfermeiro na instituição hospitalar, condição que consome grande parte de seu tempo na realização de atividades burocráticas-gerenciais, restando assim pouco espaço para que seu trabalho se torne criativo, revelando um desvio da ação cuidadora (9-11).

Ele está mais envolvido com a administração, perde o foco da atenção, prevenção e tratamento (D3).

Passa grande parte de seu tempo consumido pela administração, e você acaba perdendo o contato com ele (D4).

Essa percepção, também, foi referida em estudo realizado com profissionais da saúde, em que os enfermeiros acreditam que executam a função burocrática-administrativa por observarem que outros elementos da equipe de saúde não estão capacitados ou não desejam desempenhar essas funções administrativas, relatando, portanto, que a executam em prol do cuidado do paciente. Ressaltam também que se sentem preparados para executá-la e se demonstram organizados para tal, e que, por essa razão, outros profissionais aprovam seu serviço e o referendam (3). 
Percebe-se que a autonomia profissional, ao longo do tempo e da evolução da enfermagem, tem sido amplamente discutida para a compreensão da profissão, tanto na definição do seu próprio desafio e caracterização do seu contexto de trabalho, bem como na forma dos enfermeiros se relacionarem e demonstrarem o seu trabalho para a equipe de saúde e para a sociedade em geral (12).

Há forte tendência do enfermeiro em desenvolver funções burocráticas (10), houve relatos de que no cotidiano do profissional enfermeiro, as atividades autônomas prioritárias consistem de atividades diretamente administrativas e gerenciais.

A divisão técnica do trabalho em enfermagem e as diferentes categorias profissionais que compõem a equipe (enfermeiros, técnicos e auxiliares de enfermagem), bem como as atribuições de cada elemento definidas na Lei do Exercício Profissional da Enfermagem (Leis, Decretos, etc., 1986), propiciam este posicionamento do enfermeiro, o qual muitas vezes acaba se afastando da assistência e do cuidado direto ao paciente, realizando apenas procedimentos de maior complexidade.

Ainda quanto à atuação do enfermeiro, para os discentes ingressantes (DI) do curso de Nutrição, o profissional enfermeiro é percebido como membro da equipe de saúde que não necessariamente atua apenas no hospital, observa-se que a percepção do campo de atuação do enfermeiro está ampliada e apesar da característica muito forte e atrelada à figura do enfermeiro atuando com pessoas doentes e no ambiente hospitalar presentes no imaginário social, gradativamente observa-se que esta imagem esta mudando como é possivel verificar nos recortes dos discursos abaixo (13).

Não necessariamente atua só em hospital, em qualquer lugar e em qualquer situação ele vai estar apto para ajudar alguém que esta precisando (DI 1).

Não só no hospital, pode atuar em outros serviços (DI 2).

Já os discentes concluintes (DC) perceberam a atuação do enfermeiro numa ação de proximidade da pessoa assistida, como aquele que, efetivamente cuida e coordena as ações de enfermagem, porém é, também, possivel notar que apesar desta visão do profissional, ainda sua atuação é vinculada a prática do profissional médico, aspecto esse que se relaciona com a história da profissão novamente e das dificuldades de definições claras dos espaços comuns de saberes e fazeres entre essas duas categorias profissionais que têm suas trajetórias históricas intimamente relacionadas (3).

O enfermeiro acaba tendo mais contato com os pacientes (DC2)

Ele vai cuidar (DC 3).

E quem provê as ações (DC4). 
Precisa estar capacitado e aumentar seu conhecimento para ajudar o médico (DC5).

No que tange a atuação do enfermeiro na ótica de docentes e discentes de nutrição este é percebido como um profissional que na sua prática desenvolve atividades que extrapolam as questões apenas relacionadas às ciências norteadoras da profissão, vez que estão presentes aspectos próprios da categoria e outros que se imbricam com outras práticas pertinentes, mas complementares, porém, não específicas da enfermagem.

As RS acerca do enfermeiro são historicamente construídas, vinculam-se aos diferentes grupos e contextos sócio-culturais e, portanto formam um conjunto de conceitos, afirmações, explicações e assim, produzem e reproduzem ideologias das práticas sociais que tem raízes elaboradas no senso comum $(3,14)$.

\section{Unidade temática II - O papel do enfermeiro na equipe de saúde}

O profissional enfermeiro no desenvolvimento de sua prática, especialmente no campo assistencial, tem sido apontado como o elemento da equipe de saúde que está presente em praticamente todas as etapas do processo assistencial que envolve as ações de saúde, sejam elas preventivas, curativas ou de reabilitação, em todas as fases da vida (15).

Desempenha um importante papel na equipe de saúde, especialmente no que tange a comunicação entre os profissionais que compõem a equipe de saúde, sendo um elo essencial para garantir a assistência adequada às necessidades individuais de cada pessoa sob seus cuidados, com a implementação de ações sinérgicas em benefício do paciente, conseguindo assim, a tão almejada resolutividade no cuidado e, consequentemente o respeito da pessoa e de outros profissionais $(16,17)$. Esses aspectos estão presentes nos recortes dos discursos abaixo.

Se não tivesse o enfermeiro na área de saúde as coisas não aconteceriam (D 3).

Uma pessoa importante para levar as informações aos pacientes por ter mais contato com o mesmo (D 4).

Tem mais contato com o paciente (DC 1).

A presença constante do enfermeiro nos diferentes contextos de saúde contribui para que as RS sobre o profissional o vinculem a alguém que esta sempre disponivel para assistir e cuidar. Esse fato se reflete na imagem do papel do enfermeiro, que o atrela a uma relação de ajuda, na qual tem aspecto primordial para auxiliar na cura e, também contribuir para a auto-realização da pessoa sob seus cuidados (17), com competência técnica e científica. 
$\mathrm{Na}$ ótica dos docentes e discentes participantes deste estudo pode-se notar nos recortes abaixo a presença desses aspectos.

Tem uma formação muito ampla (DI 1).

É imprescindivel o atendimento dele (DI 1).

O paciente sabe e reconhece o enfermeiro (DC3).

Muitas vezes sua atuação é tão intensa e presente que, por vezes, o enfermeiro é percebido como um profissional que se destaca na equipe de saúde e que está mais presente no cotidiano institucional de saúde do que o próprio médico. Este fato observado nos discursos dos participantes deste estudo, talvez possa ser explicado pela formação humanística que este profissional recebe e que realiza na sua prática profissional por meio de sua presença constante, sua atenção direcionada as necessidades individuais da pessoa assistida ou da coletividade sob seus cuidados.

Acaba sendo até mais importante que o médico (DC 2).

Muito mais presente que o médico (DC 5).

O enfermeiro 'e muito mais presente que o médico (DC 3).

O papel do enfermeiro na equipe de saúde ainda é muito vinculado nas suas atividades assistenciais o que reflete as RS da profissão, que por sua vez reforçam a natureza do objeto representado (o enfermeiro), o tipo de relações que o grupo mantém com esse objeto, o sistema de valores e padrões sociais presentes no contexto em que se vive (3).

\section{Conclusoes}

Os enfermeiros foram percebidos como elementos importantes, considerados profissionais que atuam diretamente com o paciente e, que se sobressaem na equipe de saúde, especialmente por seu cuidado humanizado. Por outro lado, são percebidos também como profissionais que tem suas ações atreladas especialmente ao profissional médico, destacando-se como auxiliar do mesmo.

A percepção do enfermeiro pela população participante configurou-se como a de um profissional essencial no cuidado direto do paciente, no entanto, suas ações não foram claramente delimitadas, o que demonstra pouca clareza do real papel deste profissional no contexto da saúde. Os aspectos científicos relacionados ao ensino e pesquisa na enfermagem também não foram referidos, mostrando que, apesar dos esforços desta categoria profissional, ainda se faz necessário árduo trabalho no sentido de construção de uma imagem profissional pautada, não apenas no fazer, mas especialmente no saber para poder fazer com qualidade, ética, compromisso e distinção profissional. 


\section{Financiamento}

Conselho Nacional de Pesquisa (CNPQ) / Brasil. Bolsa de iniciação científica.

\section{Conflito de interesses}

Não existem

\section{Referência}

1. Melo C. Divisão Social do trabalho e enfermagem. São Paulo (BR): Cortez; 1986.

2. Nauderer TM, Lima MADS. Imagem da enfermeira: revisão da literatura. Rev Bras Enferm. 2005 jan/fev; 58(1): 74-77.

3. Gomes AMT, Oliveira DCA. Auto e heteroimagem profissional do enfermeiro em saúde pública: um estudo de representações sociais. Rev Latinoam Enferm. 2005 nov/dez; 13(6): 1011-8.

4. Moreira ASP, Camargo BV, Jesuíno JC, Nobrega SM (Orgs.). Perspectivas teórico-metodológicas em representações sociais. João Pessoa (BR): UFBB; [Internet] 2005 (Accesso em 27 set 2011] Disponível em: http:// www.anpepp.org.br.

5. Bardin L. Análise de conteúdo. Rio de Janeiro (BR): Edições 70; 2012.

6. Rocha SMM. O processo de trabalho da enfermagem em saúde coletiva e a interdisciplinaridade. Rev Latinoam Enferm. 2000 dez; 8(6): 96-101.

7. Leonello VM. Processo de trabalho docente no ensino superior de enfermagem: possibilidades e desafios em diferentes contextos institucionais. 2012. 164f. Tese [Doutorado]. Universidade de São Paulo, São Paulo [Internet] 2012 (Accesso em 29 mar. 2014] Disponivel em: http://www.teses.usp.br/teses/disponiveis/7/7141/tde-08102012$114214 /$ pt-br.php.

8. Boff L. Saber cuidar: ética do humano com paixão pela terra. (2 ed). Petrópolis (RJ/BR): Vozes; 2004.

9. Ferreira MAG, Pontes M, Ferreira N. Cuidar em enfermagem-percepção dos utentes. Rev facul ciências saúde. Porto: Ed. Universidade Fernando Pessoa. 2009; 6: 358-366.

10. Silva MG et. al. Processo de formação da(o) enfermeira(o) na contemporaneidade: Desafios e perspectivas. Texto \& Contexto Enferm. 2010, fev. Rio de Janeiro (BR), 19 (1); 176-84.

11. Schnoor KD. A fascinante vida de ser enfermeira. [Internet] 2012 [Accesso em 10 de abril de 2015] Disponivel em: http://www.portaleducacao.com. br/enfermagem/artigos/18866/a-fascinante-vida-deser-enfermeira\#.

12. Zimmermann A. A escolha profissional na área da saúde: a opção pela enfermagem. 2007. 240 f. Dissertação [Mestrado]: Programa de Pós-graduação em Educação, Universidade de Campinas UNICAMP, Campinas, SP, 2007.

13. Moscovici S. A representação social. São Paulo (BR): Vozes; 2010.

14. Carboni RM, Nogueira VO. Reflexões sobre as atribuições do enfermeiro segundo a lei do exercício profissional. Rev Paul Enferm, 2006 abr/jun; 25(2): 117-122. 
15. Souza GJ. Construção da identidade do enfermeiro: a experiência da profissionalização. 244p. Dissertação [Mestrado]. Universidade de Taubaté. Taubaté. 2015.

16. Zuza DC, Silva MAPD. Estudo sobre a identidade do enfermeiro em uma instituição hospitalar cooperativista. REME- Rev Min Enferm, 2007 out/dez;11(4): 420-424.

17. Phaneuf M. Comunicação, entrevista, relação de ajuda e validação. Loures (PT): Lusociência; 2005. 